\title{
MỘT SỐ GIẢI PHÁP ĐỔI MỚI CÔNG TÁC ĐÀO TẠO VÀ NGHIÊN CÚU KHOA HỌC, CÔNG NGHÊ NHẰM NÂNG CAO CHẤT LỰ̛̣NG NGUỒN NHẦN LỰC TRONG LĨNH VỰC KHOA HỌC, CÔNG NGHẸ TRÁI ĐẤT - MỎ - MÔI TRƯờNG
}

\author{
Mai Trọng Nhuận ${ }^{1}$, Trần Thanh Hải², Nguyễn Thị Hoàng Hà1, \\ Trần Hồng Thái ${ }^{3}$, Nguyễn Tài Tuệ ${ }^{1}$
}

Tóm tắt: Bài báo này khái quát thực trạng và đề xuất một số giải pháp về đổi mói công tác đào tạo và nghiên cúu khoa học, công nghệ nhằm nâng cao chất lượng nguồn nhân lực trong lĩnh vưc khoa học Trái Đất - Mỏ - Môi trương (EME). Nhũng nhu cầu về phát triển bền vĩng, xây dưng và phát triển kinh tế, xã hội xanh, tuần hoàn, carbon thấp, chống chịu cao, có khả năng chủ động ứng phó với biến đổi toàn cầu, khả năng tạo việc làm sau khi tốt nghiệp, yêu cầu về ngành nghề, nguồn nhân lực, nhu cầu xã hội,... cho thấy việc đổi mới công tác đào tạo và nghiên cứu khoa họ, công nghệ nhằm phát triển năng lục, nâng cao khả năng tạo việc làm của người học khi tốt nghiệp, đáp úng yêu cầu thực tế và bối cảnh xã hội mới nói trên trong giáo dục đại học là hết sức cấp bách. Bên cạnh đó, một số khuyến nghị đối với co sở giáo dục đại học và nhà tuyển dụng, sủ dụng nguồn nhân lục và các sản phẩm khoa học, công nghệ về lĩnh vục EME cũng được đề xuất.

Từ khóa: Đổi móit, đào tạo nguồn nhân lục, Khoa học Trái đất - Mỏ - Môi truờng, nghiên cứu khoa hoc.

Ban Biên tập nhận bài: 11/12/2019 Ngày phản biện xong: 12/12/2019 Ngày đăng bài:20/12/2019

\section{Mở đầu}

Thời đại của cuộc cách mạng khoa học và công nghệ (KHCN) hiện đại đang diễn ra nhanh chóng. Sự tiệm cận nền văn minh trí tuệ và một xã hội tin học hoá cao đã tạo nên những chuyển biến nhanh chóng về lượng cũng như về chất của toàn bộ nền kinh tế và xã hội thế giới $[10,12]$. Trong bối cảnh đó, con người với tri thức hiện đại sẽ đóng vai trò quyền lực, sức mạnh định hướng và điều khiển sự phát triển xã hội của mỗi quốc gia $[1,4,5,8]$. Chính vì vậy, các quốc gia trên thế giới đều ý thức được rằng giáo dục, trong đó có giáo dục đại học thực sự là đòn bẩy quan trọng để phát triển kinh tế và xã hội. Một quốc gia, đặc biệt là quốc gia đang phát triển hiện nay muốn phát triển và thoát khỏi sự lệ

${ }^{1}$ Đại học Quốc gia Hà Nộ

${ }^{2}$ Truò̀ng Đại học Mỏ - Địa chất

${ }^{3}$ Tổng cuc Khi tuoọng Thuỷ văn

Email:nhuanmt@vnu.edu.vn thuộc về công nghệ và kinh tế phải có một chiến lược đúng đắn phát triển con người và $\mathrm{KHCN}$, trong đó đầu tư cho giáo dục là nhiệm vụ phải được ưu tiên. Do đó, đào tạo nhân lực, bồi dưỡng và trọng dụng nhân tài là vấn đề có tầm chiến lược, là yếu tố quyết định tương lai của đất nước và giữ vai trò cốt tử đối với mỗi quốc gia $[7,9$, 13]. Vì vậy, các chính phủ ở hầu hết các quốc gia trên thế giới đều coi giáo dục là quốc sách hàng đầu. Trong lĩnh vực giáo dục nói chung, đào tạo đại học đóng vai trò quan trọng. Đây là chìa khóa cung cấp trình độ và kỹ năng $\mathrm{KHCN}$ đóng vai trò hạt nhân trong tiếp nhận tri thức và công nghệ mới, tạo nền tảng cho sáng tạo và động lực thúc đẩy nền $\operatorname{KHCN}[1,13]$. Nhận thức được vấn đề này, Việt Nam là một trong những quốc gia rất coi trọng sự phát triển của nền giáo dục đại học, đã và đang đầu tư lớn để xây dựng và củng cố nền giáo dục đại học ngày càng vững mạnh và có chất lượng. 


\section{BÀI BÁO KHOA HỌC}

Trong bối cảnh biến đổi toàn cầu (BĐTC) và cuộc Cách mạng công nghiệp lần thứ $4(\mathrm{CMCN}$ 4.0) đòi hỏi cần có sự thay đổi căn bản và toàn diện công tác đào tạo và nghiên cứu khoa học, công nghệ nhằm nâng cao chất lượng nguồn nhân lực, thích ứng với điều kiện mới. Theo Điều 49, Khoản 1, Luật Giáo dục đại học năm 2018 "Bảo đảm chất lượng giáo dục đại học là quá trình liên tục, mang tính hệ thống, bao gồm các chính sách, cơ chế, tiêu chuẩn, quy trình, biện pháp nhằm duy trì và nâng cao chất lượng giáo dục đại học" [11].

Khoa học, công nghệ Trái Đất - Mỏ - Môi trường $(\mathrm{EME})$ góp phần quan trọng đối với phát triển bền vững (PTBV), ứng phó BĐTC. Khoa học - công nghệ EME là nền tảng, giải pháp để đạt hầu hết các mục tiêu PTBV [14]. Với mục tiêu PTBV, xây dựng và phát triển kinh tế, xã hội xanh, tuần hoàn, carbon thấp, chống chịu cao, Việt Nam cần chủ động ứng phó với các $\mathrm{B} Đ T C$, bao gồm cả sự phát triển nhanh chóng của CMCN 4.0 và KHCN, trong đó có EME. Ngoài ra, nhu cầu phát triển các kỹ năng, kiến thức thích ứng với yêu cầu của công nghiệp hóa, hiện đại hóa đất nước, $\mathrm{PTBV}$ và ứng phó $\mathrm{BĐTC}$ và thách thức cũng như cơ hội của giáo dục trong nền tảng $\mathrm{CMCN}$ 4.0. Những vấn đề này là những thách thức cơ bản đòi hỏi cần có sự chuyển mình và đổi mới căn bản và toàn diện nhằm nâng cao chất lượng nguồn nhân lực của toàn xã hội và trong lĩnh vực EME nói riêng. Bài viết này giới thiệu khái quát một số thực trạng về bối cảnh và yêu cầu đổi mới công tác đào tạo và nghiên cứu khoa học, công nghệ nhằm nâng cao chất lượng nguồn nhân lực nói chung và lĩnh vực EME nói riêng. Trên cơ sở đó, một số giải pháp và khuyến nghị cũng được thảo luận và đề xuất nhằm nâng cao chất lượng nguồn nhân lực trong lĩnh vực này.

2. Bối cảnh và yêu cầu đổi mới công tác đào tạo và nghiên cứu khoa học, công nghệ EME

\subsection{Khả năng tạo việc làm}

Công tác tuyển sinh vào học nhiều ngành nói chung và lĩnh vực EME nói riêng đang ngày càng gặp khó khăn do nhiều nguyên nhân khác nhau. Một trong những nguyên nhân là cơ hội tìm kiếm việc làm. Những ngành dễ tuyển sinh có tới hơn $65 \%$ sinh viên tốt nghiệp làm việc trong khối doanh nghiệp không sử dụng ngân sách (như các tổ chức phi chính phủ, các doanh nghiệp hoặc công ty,...). Ngược lại, những ngành có vị trí việc làm trong các cơ quan nhà nước, trường học,... đang ngày càng hạn chế, mức thu nhập và đãi ngộ khi ra trường thấp đang ngày càng khó tuyển sinh, điểm chuẩn đầu vào thấp. Như vậy, vấn đề cốt lõi để sinh viên quyết định lựa chọn ngành nghề chính là khả năng có việc làm sau khi ra trường. Theo một số thống kê kết quả kiểm định giáo dục và đánh giá chương trình đào tạo (CTĐT) cho thấy các yếu tố nêu dưới đây ảnh hưởng tới khả năng tạo việc làm:

- CTĐT lạc hậu, chậm thay đổi, không quan tâm tới chuẩn đầu ra và chưa đáp ứng được yêu cầu của thực tế. Việc xây dựng các CTĐT hầu hết vẫn theo phương thức truyền thống, lạc hậu, mang tính áp đặt chủ quan của người làm chương trình mà không quan tâm tới mục tiêu lấy chuẩn đầu ra và đáp ứng nhu cầu xã hội làm thước đo. Việc tham khảo ý kiến của các bên liên quan như nhà tuyển dụng và doanh nghiệp vào việc thiết kế CTĐT không được chú trọng. Do đó, người học khi ra trường thường không có đủ kỹ năng để làm việc và thích ứng hoặc hòa nhập với môi trường làm việc của doanh nghiệp, các cơ quan, đơn vị tổ chức sử dụng KHCN EME;

- Chất lượng đào tạo chưa được chú trọng, chủ yếu chạy theo số lượng mà chưa nâng cao được chất lượng. Trong thời gian qua, việc nâng cao chất lượng đào tạo đại học đã được cả cơ quan quản lý và các cơ sở đào tạo đại học quan tâm với hàng loạt quy định và giải pháp được tiến hành, trong đó việc thể chế hóa đánh giá chất lượng đào tạo, triển khai đánh giá chất lượng nhà 
trường và các $\mathrm{CTÐT} \mathrm{theo} \mathrm{các} \mathrm{quy} \mathrm{định} \mathrm{của} \mathrm{Bộ}$ Giáo dục và Đào tạo cũng như việc các trường đại học chủ động tham gia vào các thang đánh giá, kiểm định chất lượng theo chuẩn quốc tế, khu vực là những bước tiến mới. Tuy nhiên, chất lượng đào tạo đại học còn nhiều hạn chế, yếu kém, bất cập nhưng chậm được khắc phục. Nội dung, CTĐT, phương pháp đào tạo vẫn lạc hậu, chậm đổi mới, chậm hiện đại hóa, chưa gắn chặt đào tạo với thực tiễn sản xuất, nghề nghiệp và sự phát triển của công nghệ. Việc giảng dạy lấy giảng đường làm trung tâm và phương pháp truyền đạt nặng tính lý thuyết, thụ động, thiếu trực quan, ít thực hành đã kìm hãm tính chủ động sáng tạo, kỹ năng thực hành của người học. Rất nhiều doanh nghiệp phải đào tạo lại nguồn nhân lực sau khi tốt nghiệp từ các trường đại học;

- Đội ngũ giảng viên yếu, có trình độ không đồng đều, chậm chuyển đổi nên chưa đáp ứng nhu cầu thực tế. Đa số giảng viên ở các trường đại học vẫn có trình độ dưới tiến sĩ và không tham gia vào các hoạt động nghiên cứu khoa học. Vẫn còn giảng viên có năng lực ngoại ngữ yếu. Do đó, tính cập nhật thực tiễn và sự phát triển $\mathrm{KHCN}$ chậm, khả năng sáng tạo, cập nhật thực tiễn thấp dẫn tới giáo điều, bảo thủ và lạc hậu trong cập nhật chương trình, kiến thức và đổi mới phương pháp dạy học;

- Phòng thí nghiệm, phương tiện, thiết bị và công cụ phục vụ cho giảng dạy và thực hành thiếu thốn, lạc hậu và không đáp ứng được yêu cầu giảng dạy và nghiên cứu khoa học nên hạn chế thời gian nghiên cứu và thực hành của cả thầy và trò. Mức thu nhập thấp làm cho đời sống của giảng viên gặp nhiều khó khăn, không khuyến khích giảng viên tận tâm với nghề;

- Năng lực sinh viên chưa đáp ứng yêu cầu thực tế. Do phương pháp dạy học chậm đổi mới, chưa chú trọng việc rèn luyện kỹ năng và thúc đẩy khả năng sáng tạo, chủ động của người học dẫn đến sự thụ động, phụ thuộc và kìm hãm sự sáng tạo của sinh viên. Bên cạnh đó, kỹ năng về ngoại ngữ của đa số sinh viên không đáp ứng được những yêu cầu tối thiểu trong công việc. Ngoài ra, các kỹ năng mềm khác như giao tiếp, văn hóa ứng xử, ý thức trách nhiệm và tuân thủ kỷ luật của sinh viên chưa cao;

- Khả năng thích ứng với thay đổi nhanh chóng của xã hội và công nghệ mới của người học kém. Do CTĐT được thiết kế một cách chủ quan, chậm chuyển đổi, phương pháp đào tạo lạc hậu mà khả năng tự điều chỉnh, thích ứng và bắt kịp với sự thay đổi nhanh chóng của công nghệ, trong đó có $\mathrm{CMCN}$ 4.0, IOTS, máy học còn hạn chế;

- Nhà nước thiếu những quyết sách đồng bộ và hợp lý ở tầm vĩ mô, trong đó có đầu tư về cơ sở vật chất, tự chủ đại học, chính sách đãi ngộ và thù lao cho giảng viên chưa đáp ứng yêu cầu thực tế, thiếu sự đồng thuận của xã hội, chưa thuận lợi cho giáo dục phát triển.

\section{2. Đòi hỏi ngành nghề - Nhu cầu nhân lục}

Yêu cầu PTBV, ứng phó BĐTC, $\mathrm{CMCN} 4.0$ và sự phát triển mạnh mẽ của công nghiệp hóa, hiện đại hóa trong đó các công cụ sản xuất ngày càng được hiện đại hóa, chuyên môn hóa và tự động hóa làm cho mỗi cá nhân tham gia vào hoạt động sản xuất đóng vai trò là một mắt xích trong dây chuyền công nghệ. Do đó, thị trường lao động hiện nay ở Việt Nam đang có những đòi hỏi ngày càng khắt khe về kỹ năng, trình độ chuyên môn, kỷ luật và tính chuyên nghiệp cao hơn. Chính vì vậy, việc đào tạo theo phương thức truyền thống, nặng về lý thuyết không còn phù hợp với đòi hỏi thực tế và sinh viên tốt nghiệp nếu không có được những tiêu chuẩn nêu trên sẽ khó có thể hòa nhập với môi trường làm việc và đòi hỏi ngày càng cao của người sử dụng nguồn nhân lực (doanh nghiệp, cơ quan, tổ chức,...).

Kinh nghiệm thực tế cho thấy, những ngành đào tạo có sự kết hợp giữa nhà trường và doanh nghiệp, trong đó sinh viên được thực hành thực tập tại doanh nghiệp trong thời gian chính khóa thì cơ hội có việc làm thường rất cao (có khi tới $100 \%$ số sinh viên tốt nghiệp) so với sinh viên chỉ được học trong trường mà không có thực hành tại doanh nghiệp. Bên cạnh đó, những ngành được các bên liên quan như các nhà sử 
dụng lao động tham gia vào hoạt động đào tạo (xây dựng CTĐT, tham gia giảng dạy và hướng dẫn thực tập,...), thì sinh viên dễ xin việc và có cơ hội lựa chọn việc làm tốt hơn do đáp ứng được các yêu cầu về trình độ và kỹ năng của doanh nghiệp. Tuy nhiên, hiện nay sự kết hợp giữa các cơ sở đào tạo và doanh nghiệp trong lĩnh vực EME còn tương đối hạn chế.

Thực tế hiện nay, nhu cầu về nguồn nhân lực EME với chất lượng thông thường, đáp ứng yêu cầu thông thường ngày càng giảm nhưng nhu cầu về nguồn nhân lực với chất lượng cao, đáp ứng yêu cầu mới, phù hợp bối cảnh mới ngày càng tăng.

Bên cạnh yêu cầu trong nước, nguồn nhân lực cần thích ứng với các chính sách và xu hướng toàn cầu, trong khu vực cũng như sự dịch chuyển nguồn nhân lực chất lượng cao của $\mathrm{ASEAN}$ và chuyển dịch cơ cấu nhân lực do tác động tự do hóa và toàn cầu hóa,...

\subsection{Giáo dục 4.0}

Giáo dục 4.0 là giáo dục với sự thay đổi dựa trên chuẩn đầu ra (Bảng 1) trong thời đại $\mathrm{CMCN}$ 4.0. Trong đó, đòi hỏi người học có kỹ năng và khả năng đáp ứng những thay đổi, có khả năng sáng tạo và có năng lực học tập suốt đời,... Giáo dục 4.0 vừa là cơ hội, vừa là thách thức đòi hỏi sự đổi mới về KHCN, đào tạo nói chung và lĩnh vực EME nói riêng.

Bảng 1. Một số điểm khác nhau giũa giáo dục các giai đoạn

\begin{tabular}{|c|c|c|c|c|}
\hline Đặc điểm & $\begin{array}{c}\text { Trước } 1980 \\
\text { Giáo dục }\end{array}$ & $\begin{array}{c}\text { 1980s } \\
\text { Giáo dục } 2.0\end{array}$ & $\begin{array}{c}\text { 1990s } \\
\text { Giáo dục } 3.0\end{array}$ & $\begin{array}{c}2000 s \\
\text { Giáo dục } 4.0\end{array}$ \\
\hline Trọng tâm & Giáo dục & Tuyển dụng & Tạo tri thức & Đổi mới và tạo giá trị \\
\hline $\begin{array}{l}\text { Chương trình dạy } \\
\text { học (curr.) }\end{array}$ & Đơn ngành & Liên ngành & Đa ngành & Xuyên ngành \\
\hline Công nghệ & Bút chì \& giấy & $\begin{array}{l}\text { Máy tính cá } \\
\text { nhân \& laptop }\end{array}$ & $\begin{array}{l}\text { Internet \& Di } \\
\text { dộng }\end{array}$ & IoT và $A I$ \\
\hline $\begin{array}{l}\text { Trình độ Kỹ thuật } \\
\text { số }\end{array}$ & $\begin{array}{l}\text { Digital } \\
\text { Refugees }\end{array}$ & $\begin{array}{l}\text { Digital } \\
\text { Immigrants }\end{array}$ & $\begin{array}{l}\text { Digital } \\
\text { Natives }\end{array}$ & Digital Citizens \\
\hline Giảng dạy & Một chiều & Hai chiều & Đa chiều & Mọi nơi \\
\hline Trường học & Gạch và vữa & $\begin{array}{l}\text { Gạch và Nhắp } \\
\text { chuột }\end{array}$ & Mạng lưới & $\begin{array}{l}\text { Hệ sinh thái khởi } \\
\text { nghiệp }\end{array}$ \\
\hline Đầu ra & $\begin{array}{l}\text { Những người } \\
\text { lao động lành } \\
\text { nghề }\end{array}$ & $\begin{array}{l}\text { Những người lao } \\
\text { động có tri thức }\end{array}$ & $\begin{array}{l}\text { Những người } \\
\text { dồng kiến tạo } \\
\text { kiến thức }\end{array}$ & $\begin{array}{l}\text { Doanh nhân, những } \\
\text { nhà khởi nghiệp và } \\
\text { sáng tạo đổi mới }\end{array}$ \\
\hline
\end{tabular}

\subsection{Nhu cầu xã hội và tâm lý người học}

Những năm gần đây, số người học đại học hàng năm ở Việt Nam không tăng do tác động của thay đổi dân số, đa dạng hóa ngành nghề và cơ hội việc làm, trong đó tăng trưởng công nghiệp và đa dạng hóa ngành nghề tạo ra nhiều việc làm phổ thông, thay đổi cơ cấu ngành nghề.

Khi tham gia học tập, người học đưa ra những lựa chọn ngành nghề dựa vào nhiều tiêu chí, trong đó có sự đam mê nghề nghiệp, môi trường làm việc sau tốt nghiệp, cơ hội việc làm và chi phí đào tạo hợp lý. Gần đây, đã có sự thay đổi đáng kể trong việc lựa chọn cơ sở đào tạo dựa vào tổng mức chi phí học tập. Nhiều người học hiện nay khi lựa chọn môi trường học tập dựa trên hai yếu tố chính là tổng chi phí đào tạo và việc làm, trong đó mong muốn việc làm là vấn đề ưu tiên chứ không phải là học phí. Phần lớn sinh viên và phụ huynh cho rằng mức học phí cao không quá quan trọng mà quan tâm nhiều đến các yếu tố chi phối khác như: cơ hội có việc làm; mức thu nhập; cam kết có việc làm; quá trình xin việc làm và chi phí cho việc xin việc, trong đó việc không phải mất thêm chi phí xin việc ngoài tổng chi phí học tập thường được cân nhắc và ưu tiên lựa chọn.

\subsection{Cạnh tranh giáo duc}

Trong nước, mạng lưới giáo dục đại học đã phát triển nhanh chóng và đang tiếp tục mở rộng trong khi đó số người học đang có xu thế giảm sút, dẫn tới cạnh tranh mạnh mẽ trong tuyển sinh. Bên cạnh đó, các trường đại học quốc tế mở rộng 
mạng lường đào tạo, thu hút người học, có chiến lược marketing tốt, có chất lượng trong bối cảnh mức sống trong nước gia tăng tạo điều kiện cho một bộ phận người học tiềm năng đi tìm cơ hội học tập ở nước ngoài.

\subsection{Thách thức trong phát triển công tác} đào tạo và nghiên cứu khoa học, công nghệ EME

Việc phát triển nguồn nhân lực EME đang tồn tại một số vấn đề lớn sau:

- Tư duy manh mún và chậm tiến, do xuất phát chủ yếu từ chính các chuyên ngành, từ cơ sở đào tạo, nghiên cứu;

- Chưa thực sự xuất phát từ nhu cầu, yêu cầu mới của phát triển kinh tế - xã hội, PTBV, ứng phó BĐTC, của các bên liên quan;

- Không dựa trên tầm nhìn và chiến lược vĩ mô, dài hạn và nhất quán;

- Chưa có sự gắn kết chặt chẽ giữa đào tạo nguồn nhân lực với thực hiện các đề tài, dự án, chương trình $\mathrm{KHCN}$;

- Thiếu định hướng ưu tiên của Nhà nước. Nhiều ngành, chuyên ngành thuộc EME có tính đặc thù, có tầm quan trọng trong phát triển khoa học và kinh tế xã hội, quản lý ngành và quốc gia, lãnh thổ. Tuy nhiên, tầm quan trọng này chưa được nhìn nhận đúng mức và do đó hiện vẫn chưa có được sự quan tâm và ưu tiên đầu tư cũng như đặt hàng đào tạo của các nhà tuyển dụng, sử dụng lao động. Môi trường làm việc của nhiều lĩnh vực EME thường là các cơ quan Nhà nước với mức thù lao thấp, điều kiện làm việc chưa hấp dẫn. Những yếu tố trên làm cho lĩnh vực
EME khó thu hút người học.

- Thiếu sự kết nối, hợp tác và hỗ trợ hoạt động giữa các bên liên quan (cơ quan quản lý, doanh nghiệp và xã hội, ...) với các cơ sở đào tạo về: (i) Đánh giá, dự báo đặt hàng số lượng, chất lượng, yêu cầu sử dụng nguồn nhân lực, sản phẩm KHCN EME; (ii) Phát triển công nghệ và chuyển giao tri thức; (iii) Tổ chức đào tạo và (iv) Nghiên cứu, ứng dụng KHCN EME.

3. Một số giải pháp đổi mới công tác đào tạo và nghiên cứu khoa học, công nghệ EME

\subsection{Giải pháp chung}

Một số giải pháp đổi mới công tác đào tạo và nghiên cứu khoa học, công nghệ được kiến nghị ở đây bao gồm:

- Lựa chọn, áp dụng sáng tạo các bài học về quản trị chất lượng (dựa vào quản trị đại học tiên tiến): (i) Luôn chú trọng chiến lược (sứ mạng, tầm nhìn, tính đến đáp ứng cao và nhanh yêu cầu phát triển đất nước, vùng, địa phương, BĐTC, yêu cầu, sự hài lòng của các bên liên quan); (ii) Mọi hoạt động cần được thực hiện theo quản trị đại học tiên tiến và đảm bảo chất lượng về Chiến lược - Hệ thống - Chức năng - Kết quả; (iii) Giám sát và cải tiến liên tục; (iv) Đáp ứng yêu cầu, sự hài lòng của các bên liên quan là điểm tham chiếu quan trọng đặc biệt; (v) Sử dụng công cụ IQA (đảm bảo chất lượng bên trong) là “động lực nội tại”, EQA (đảm bảo chất lượng bên ngoài ) là "áp lực từ bên ngoài” (Hình 1).

- Quản trị đại học dựa vào mô hình đảm bảo chất lượng phối hợp (Hình 2).

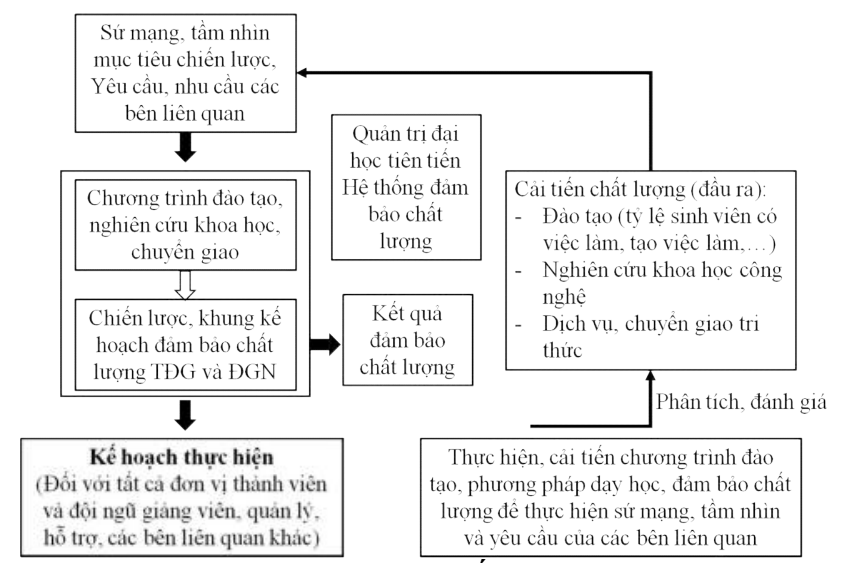

Hình 1. Quản trị đại học tiên tiến 


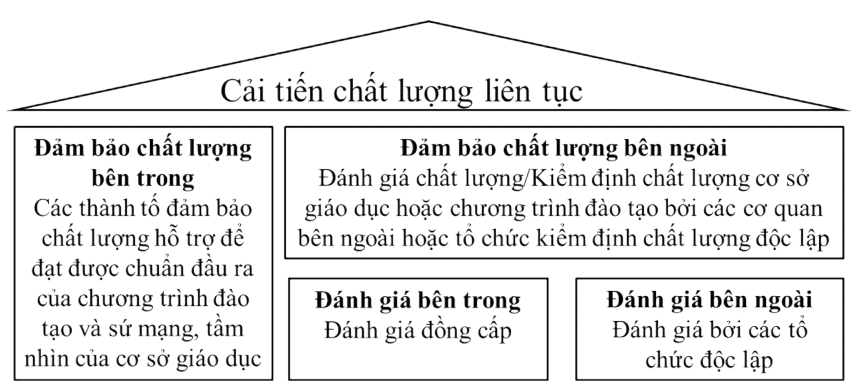

Cam kết của lãnh đạo - Kế hoạch chiến lược-Văn hóa chất lượng

Hình 2. Quản trị đại học phối hợp

- Đào tạo dựa theo chuẩn đầu ra: đào tạo đảm bảo các nguyên tắc: (i) Tập trung phát triển năng lực/mục tiêu/chuẩn đầu ra CTĐT, trong đó chú trọng tới khả năng có và tạo việc làm của người học tốt nghiệp; (ii) Thiết kế chương trình dạy học ngược; (iii) Tương thích định hướng: Giảng dạy - Học tập - Đánh giá hướng tới phát triển và đạt chuẩn đầu ra; (iv) Tạo ra cơ hội học tập trải nghiệm, học qua làm trong và ngoài nhà trường; (v) Vận dụng sáng tạo CDIO (Conceive - Design -Implement - Operate) phù hợp với điều kiện cụ thể; (vi) Hợp tác chặt chẽ và hiệu quả với các bên liên quan để thực hiện CTĐT, phương pháp đào tạo, nghiên cứu khoa học, phát triển công nghệ và chuyển giao tri thức đáp ứng yêu cầu của các bên liên quan.

- Tham vấn, hợp tác toàn diện với các bên liên quan bao gồm khảo sát ý kiến, nhu cầu, yêu cầu, mức độ hài lòng về đào tạo, nghiên cứu khoa học, phục vụ xã hội,...

- Thực hiện đầy đủ: (i) Các tiêu chuẩn kiểm định chất lượng CTĐT (Thông tư 04/2016 của Bộ Giáo dục và Đào tạo [2]), trong đó lưu ý tiêu chuẩn 10 về nâng cao chất lượng, tiêu chuẩn 11 về kết quả đầu ra,...); (ii) Các tiêu chuẩn kiểm định chất lượng cơ sở giáo dục đại học (Thông tư 12/2017 của Bộ Giáo dục và Đào tạo [3]), đặc biệt là tiêu chuẩn 12 về nâng cao chất lượng, tiêu chuẩn 22 - 25 về kết quả các hoạt động đào tạo, nghiên cứu khoa học, phục vụ cộng đồng, kết quả tài chính và thị trường...;

- Lựa chọn, áp dụng sáng tạo các bài học hay về phát triển, cải tiến CTĐT phù hợp với đơn vị mình;
Việc xây dựng, phát triển CTĐT dựa vào tiếp cận PDCA (Plan, Do, Check, Act) (Hình 3) và CDIO nên thực hiện theo các bước sau đây:

Bước 1: Thành lập nhóm xây dựng, phát triển, cải tiến CTĐT;

Bước 2: Nghiên cứu, phát hiện nhu cầu, yêu cầu (hiện tại, tương lai) của các bên liên quan về nguồn nhân lực dự kiến đào tạo;

Bước 3: Tra cứu, thu thập, phân tích tài liệu và tham chiếu về nhu cầu, yêu cầu chuẩn đầu ra, mục tiêu, nội dung CTĐT của các cơ sở giáo dục đại học trong và ngoài nước liên quan đến CTĐT dự kiến mở mới hoặc CTĐT cần cập nhật/cải tiến;

Bước 4: Xây dựng đề cương đề án mở hoặc điều chỉnh/cải tiến CTĐT;

Bước 5: Soạn thảo tóm tắt nội dung cốt lõi của CTĐT mới, CTĐT cần điều chỉnh/cải tiến;

Bước 6: Hội thảo cấp Khoa về nội dung cốt lõi của CTĐT, điều chỉnh nội dung chương trình theo kết quả hội thảo;

Bước 7: Soạn thảo phiếu hỏi các bên liên quan;

Bước 8: Điều tra theo phiếu và phỏng vấn các bên liên quan về CTĐT mới/cải tiến;

Bước 9: Dựa vào kết quả nêu ở Bước $3-8$, đặc biệt là Bước 8 để xây dựng dự thảo CTĐT mới hoặc cải tiến;

Bước 10: Xây dựng chương trình và phương pháp dạy học;

Bước 11: Soạn thảo phiếu xin ý kiến về CTĐT, chương trình và phương pháp dạy - học;

Bước 12: Điều tra theo phiếu và, phỏng vấn;

Bước 13: Dựa vào kết quả Bước 12 , hoàn 
thiện CTĐT, chương trình dạy học;

Bước 14: Xây dựng đề án (điều chỉnh, hoặc mở mới) ngành đào tạo;

Bước 15: Hội thảo cấp Khoa mở rộng, mời đại diện các bên liên quan dự và hoàn thiện đề án;
Bước 16: Trình hội đồng khoa học đào tạo Trường và chỉnh sửa theo yêu cầu của Nhà trường;

Bước 17: Trình cấp thẩm quyền phê duyệt;

Bước 18: Phát triển các điều kiện đảm bảo chất lượng đủ để được phép tổ chức đào tạo.

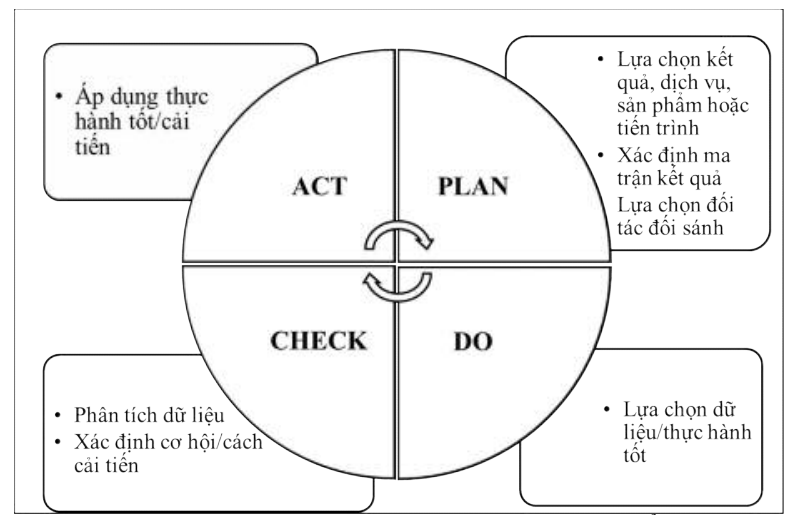

Hình 3. Tiếp cận PDCA (Lập kế hoạch - Triển khai -Kiểm tra-Cải tiến)

Xây dựng, phát triển, cải tiến CTĐT theo các cách tiếp cận và phương pháp nêu trên là một trong những giải pháp quan trọng nhất để tận dụng cơ hội, chuyển hoá các thách thức, phát triển Khoa, các ngành, chuyên ngành đáp ứng cao và nhanh nhu cầu của các bên liên quan, thể hiện ở các khía cạnh sau:

+ Bước khởi đầu quan trọng nhất là thay đổi nhận thức, thói quen, phát triển tầm nhìn để áp dụng sâu rộng quản trị đại học tiên tiến và đảm bảo chất lượng khi xây dựng, phát triển, cải tiến CTÐT;

+ Ủu tiên việc đáp ứng cao, nhanh nhu cầu, yêu cầu, sự hài lòng các bên liên quan;

+ Xây dựng, phát triển, cải tiến CTĐT, văn hoá chất lượng là nhiệm vụ và lợi ích của tất cả cán bộ viên chức của Khoa và Nhà trường, trước hết là lãnh đạo, cán bộ quản lý và giảng viên;

+ Hợp tác hiệu quả và hài hòa lợi ích với các bên liên quan, các Khoa, các đơn vị trong và ngoài Nhà trường là chìa khoá thành công khi thực hiện các bước, các nhiệm vụ nói trên.

Phát triển, cải tiến và đảm bảo chất lượng CTĐT tốt nhất nên triển khai theo:

+ Hướng dẫn, tập huấn về: (i) Tạo ra, phát hiện các nhu cầu mới về nguồn nhân lực, lấy ý kiến các bên liên quan; (ii) Nhận thức về kiểm định chất lượng, bộ tiêu chuẩn, cách tiếp cận, cách khắc phục các vướng mắc, khó khăn khi xây dựng, phát triển, cải tiến, vận hành CTĐT; (iii) Làm báo cáo tự đánh giá và chuẩn bị hồ sơ, thông tin, dữ liệu về chương và thực hiện CTĐT;

+ Lấy ý kiến các bên liên quan về nhu cầu, yêu cầu về nguồn nhân lực dự kiến đào tạo, cải tiến chất lượng;

+ Triển khai xây dựng ý tưởng (mục tiêu, chuẩn đầu $\mathrm{ra}, . .$. ) CTĐT;

+ Chuẩn bị hồ sơ, thông tin, dữ liệu ngay từ khi bắt đầu xây dựng, phát triển, cải tiến CTĐT;

+ Làm việc, trao đổi với chuyên gia;

+ Tham dự buổi báo cáo sơ bộ của đoàn đánh giá ngoài;

+ Tham dự họp và trình bày báo cáo tại phiên họp Hội đồng Kiểm định chất lượng của Trung tâm kiểm định chất lượng;

+ Sử dụng Báo cáo đánh giá ngoài để: i) Hiểu đúng hơn điểm mạnh, tồn tại, khuyến nghị; ii) Xây dựng và thực hiện chiến lược, kế hoạch cải tiến chất lượng theo khuyến nghị;

+ Đảm bảo chất lượng CTĐT mới: Chuẩn bị minh chứng, hồ sơ và dựa vào ý kiến các bên liên quan theo các mốc tham chiếu từng tiêu chí ngay 
từ khi xây dựng, tổ chức thực hiện, đánh giá, cải tiến chương trình trên cơ sở áp dụng sâu rộng các thành tựu của $\mathrm{CMCN}$ 4.0, đại học số, đại học thông minh;

- Lựa chọn, áp dụng sáng tạo các bài học hay từ đảm bảo chất lượng một số trường đại học CTĐT phù hợp với đơn vị mình:

+ Được tiến hành tổng thể - hệ thống, theo một chiến lược đảm bảo chất lượng sáng tạo, khả thi, một khung đảm bảo chất lượng tập trung, nhất quán;

+ Đảm bảo chất lượng và đánh giá chất lượng tốt dựa vào: (i) Kết quả: Chuẩn đầu ra CTĐT theo các tiêu chuẩn 11 (Thông tư 04/2016) và 21-25 Thông tư 12/2017 của Bộ Giáo dục và Đào tạo, tập trung vào phát triển chuẩn đầu ra CTĐT, các sản phẩm hữu dụng về $\mathrm{KHCN}$, chuyển giao tri thức; (ii) Quản trị đại học tiên tiến, tích hợp quản trị sáng tạo, theo quy định và theo nguyên lý, PDCA, CDIO, tương thích có định hướng (constructive alignment); (iii) Các bên liên quan: người đánh giá khách quan chất lượng nhà trường, CTĐT thông qua mức độ đáp ứng yêu cầu, nhu cầu và hài lòng của họ,...; (iv) Tổ chức học tập (Learning organization); (v) Báo cáo tự đánh giá với các khung logic từng tiêu chuẩn, được xây dựng theo quy trình hợp lý; (vi) Đối sánh trong nước và quốc tế về nội dung liên quan (chương trình, kết quả đào tạo và nghiên cứu khoa học);

+ Chiến lược đảm bảo chất lượng/đảm bảo chất lượng bên trong tốt: (i) Là công việc của toàn trường, của mọi cán bộ, sinh viên: (ii) Cần thực hiện đầy đủ khung đảm bảo chất lượng cơ sở giáo dục đại học, CTĐT (nhất là khâu xây dựng và thực hiện mục tiêu, chuẩn đầu ra); (iii) Định hướng thị trường/đáp ứng cao và nhanh nhu cầu xã hội, các bên liên quan bằng cách thực hiện đầy đủ, theo đúng chu trình PDCA; (iv) Dựa vào đánh giá, dự báo nhu cầu, sự hài lòng các bên liên quan, thu thập, đánh giá, xử lý, phản hồi, tiếp thu ý kiến của họ theo quy trình và vận hành thống nhất, tránh chồng chéo, khác biệt; Nghiên cứu, sử dụng $\mathrm{AI}$ để tổng hợp, xử lý, chuyển ý kiến của các bên liên quan đến các bộ phận để cải tiến chất lượng; (v) Phát triển và ổn định đội ngũ giảng viên chuyên ngành trình độ cao, tâm huyết, tạo môi trường và chính sách đãi ngộ phù hợp thúc đẩy sáng tạo, nghiên cứu khoa học, phát triển công nghệ và chuyển giao tri thức; Nâng cao năng lực giảng viên nghiên cứu đáp ứng yêu cầu cao của xã hội, năng lực của các bên liên quan, nhất là giảng viên, cán bộ quản lý, sinh viên thực hiện việc điều chỉnh tích cực để đạt chuẩn đầu ra; (vi) Phát triển các phòng thí nghiệm chuyên ngành, cơ sở đáp ứng yêu cầu đạt chuẩn đầu ra; (vii) Được triển khai theo mô hình tổng công trình sur: Từng nội dung, tiêu chí đảm bảo chất lượng được triển khai theo theo một đầu mối thống nhất: đầu mối thiết kế, tổ chức và điều phối thống nhất thực hiện ở các cấp (trường/bộ phận/khoa,...) theo từng hoạt động; (viii) Có cơ sở dữ liệu tích hợp đầy đủ và liên thông về đảm bảo chất lượng, phương pháp dạy học, người học, giảng viên, cán bộ hỗ trợ,... dễ dàng truy xuất tuỳ biến theo yêu cầu người sử dụng cho cả trường, khoa và theo từng $\mathrm{CTĐT;} \mathrm{(ix)} \mathrm{Các} \mathrm{bên}$ liên quan (giảng viên, cán bộ quản lý, hỗ trợ, người học, các khoa, bộ môn, viện, trung tâm nghiên cứu,...) được nâng cao năng lực, được trao quyền tự chủ, tự chịu trách nhiệm cao để thực hiện đảm bảo chất lượng bằng hành động sáng tạo và tinh thần trách nhiệm cao;

Phát huy ưu điểm của quản trị theo nguyên lý, quy định quản trị doanh nghiệp (dám làm, dám học hỏi, dám thất bại để thành công), quản trị đại học tiên tiến, quản trị sáng tạo của Nhà trường để nâng cao chất lượng thông qua: (i) Hài hoà, cân bằng phát huy thế mạnh của Nhà trường với đáp ứng cao yêu cầu đất nước, xã hội, biến động phức tạp của thị trường lao động và yêu cầu của CMCN 4.0; (ii) Có chính sách khuyến khích vật chất, tinh thần để đẩy mạnh đảm bảo chất lượng; (iii) Tích hợp thống nhất, đồng bộ hoá CDIO, đánh giá chất lượng theo tiêu chuẩn của Mạng lưới các trường đại học Đông Nam Á (AUN-QA), chuẩn Việt Nam, chuẩn riêng của Nhà trường để tạo giá trị gia tăng, tránh rối loạn, 
phức tạp; (iv) Kiến nghị các giải pháp chung từ vĩ mô (nhà nước, xã hội về sử dụng sinh viên tốt nghiệp,...) và thực hiện các giải pháp do Nhà trường quyết định để tăng cường đảm bảo chất lượng; (v) Làm giỏi, viết giỏi, báo cáo giỏi, lưu trữ tốt thông tin, tài liệu, minh chứng.

Đảm bảo chất lượng bền vững: (i) Dựa vào tạo dựng, phát triển văn hoá nhà trường, văn hoá chất lượng thông qua các quy định, hướng dẫn, yêu cầu của đảm bảo chất lượng (vận dụng các quy định đảm bảo chất lượng, các tiêu chuẩn, tiêu chí của kiểm định chất lượng (ví dụ theo Thông tư 12/2017 và 04/2016 của Bộ Giáo dục và Đào tạo), quy định và đảm bảo chất lượng của Nhà trường vào trong văn bản quản lý điều hành của nhà trường như các quy chế, quy định, hướng dẫn đối với mọi hoạt động của tập thể, cá nhân,... để đảm bảo chất lượng được thực hiện một cách "tự nhiên"; (ii) Lưu trữ minh chứng ngay từ đầu của từng hoạt động đảm bảo chất lượng, theo từng tiêu chí kiểm định chất lượng đối với từng CTÐT; (iii) Áp dụng các thành tựu của CMCN4.0, đại học số, đại học thông minh; (iv) Sự đam mê, trách nhiệm, quyết tâm của lãnh đạo các cấp, của giảng viên, cán bộ quản lý và các bên liên quan khác là yếu tố quyết định thành công và hiệu quả đảm bảo chất lượng; (v) Quản trị rủi ro - yếu tố rất quan trọng cho đảm bảo chất lượng; (vi) Phát huy quan hệ tương hỗ giữa đảm bảo chất lượng và đổi mới phương pháp dạy học; Đảm bảo chất lượng bên trong, xây dựng văn hoá chất lượng là nền tảng quyết định cho đổi mới phương pháp dạy học thành công bền vững; (vii) Đổi mới mô hình đào tạo (chẳng hạn đào tạo kỹ sư + nhà khoa học + nhà lãnh đạo quản lý, cử nhân, kỹ sư EME+ $\mathrm{AI}, .$. ) và phương pháp dạy học đáp ứng yêu cầu, nhu cầu của các bên liên quan dựa vào và tuân thủ đảm bảo chất lượng để đạt mục tiêu nâng cao chất lượng một cách bền vững;

Phát huy vai trò của bộ môn là đơn vị đặc biệt quan trọng trong đảm bảo chất lượng và đổi mới phương pháp dạy học vì bộ môn: (i) Là mắt xích cuối cùng trong hệ thống đảm bảo chất lượng; (ii) Trực tiếp quản lý chuyên môn - giảng dạy, nghiên cứu khoa học, phục vụ cộng đồng, xã hội của giảng viên và sinh viên; (iii) Địa bàn chuyên môn gần gũi nhất để đổi mới phương pháp dạy học.

Giảng viên là yếu tố quyết định sự bền vững của đảm bảo chất lượng, văn hoá chất lượng và đổi mới phương pháp dạy học hiệu quả nhất, đáp ứng nhu cầu của các bên liên quan.

\subsection{Các giải pháp đặc thù lĩnh vục EME}

Mục tiêu nâng cao liên tục chất lượng nguồn nhân lực EME là: phát triển năng lực (kiến thức, kỹ năng, phẩm chất đạo đức - năng lực tự chủ, tự chịu trách nhiệm), nâng cao khả năng có, tạo việc làm của người học sau khi tốt nghiệp, đáp ứng yêu cầu mới, bối cảnh mới nói trên;

Giải pháp thực hiện đảm bảo chất lượng và nâng cao chất lượng nguồn nhân lực EME liên tục phù hợp với yêu cầu và bối cảnh mới nói trên (Hình 4), trọng tâm là:

- Phát triển các nghiên cứu mới, phát hiện mới, tạo nhu cầu mới đáp ứng yêu cầu và bối cảnh mới;

- Đảm bảo chất lượng theo chuẩn quốc tế, khu vực phù hợp với Việt Nam;

- Đổi mới, cải tiến CTĐT hiện có, phát triển CTĐT mới đáp ứng yêu cầu mới, bối cảnh mới;

- Đổi mới, cải tiến phương pháp dạy học, kiểm tra đánh giá hiện có, phát triển các phương pháp dạy học, kiểm tra đánh giá mới;

- Tích hợp nghiên cứu dựa vào đào tạo và đào tạo dựa vào nghiên cứu;

- Chọn lọc, áp dụng sáng tạo các bài học hay của các trường đại học trong và ngoài nước phù hợp với đơn vị mình về đảm bảo chất lượng, phát triển, cải tiến CTĐT, đổi mới phương pháp dạy học; 


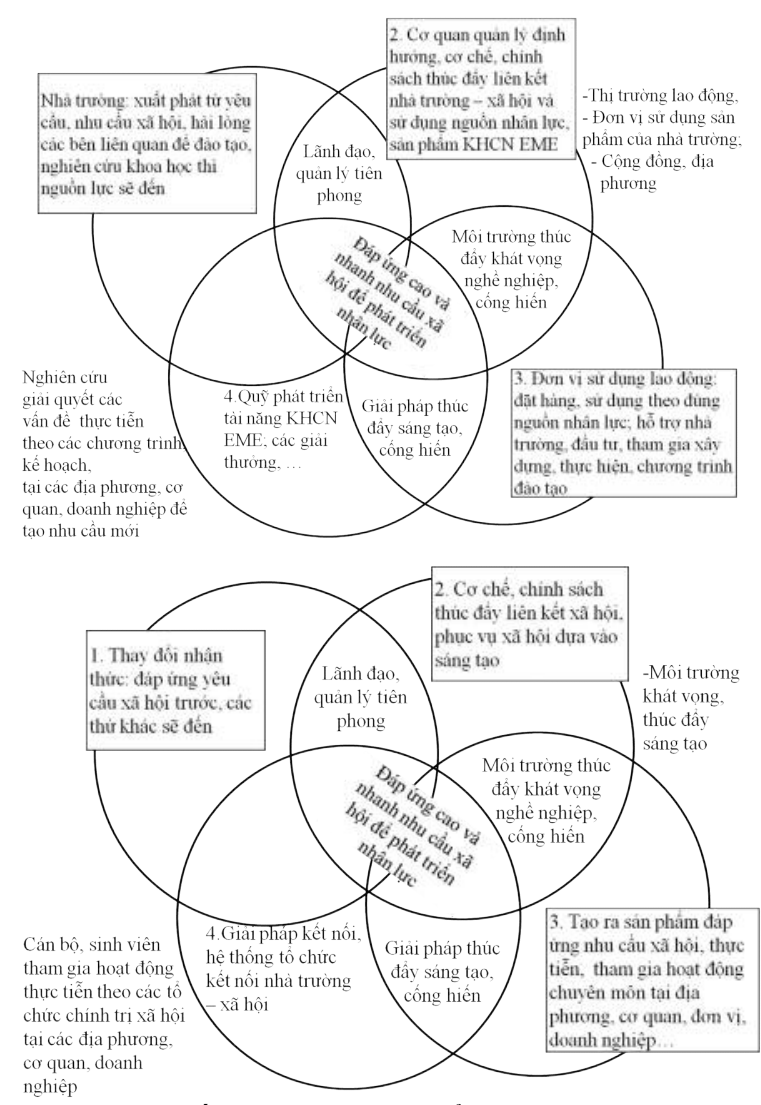

Hình 4. Một số giải pháp phát triển EME

Một số giải pháp đặc thù đổi mới đào tạo và nghiên cứu khoa học, công nghệ EME có thể nêu như sau (Hình 4):

- Thực hiện quan điểm "Đáp ứng cao và nhanh nhu cầu, yêu cầu phát triển đất nước, xã hội, các bên liên quan các thứ tốt đẹp sẽ đến";

- Đánh giá, dự báo nhu cầu, yêu cầu của công nghiệp hoá, hiện đại hoá, PTBV đất nước, ứng phó BĐTC, tận dụng CMCN 4.0,...;

- Xây dựng, cập nhật, thực hiện các CTĐT và nghiên cứu khoa học, chuyển giao tri thức;

- Xây dựng và thực hiện chiến lược đào tạo, nghiên cứu khoa học;

- Phát triển đội ngũ giảng viên, nghiên cứu viên, cán bộ quản lý và hệ thống tổ chức, cơ sở vật chất đáp ứng yêu cầu mới, bối cảnh mới;

- Đẩy mạnh kết nối, hợp tác với xã hội, các bên liên quan, trọng tâm gồm: (i) Xác định, đánh giá, dự báo, chia sẻ thông tin về nhu cầu, yêu cầu của xã hội, của công nghiệp hóa - hiện đại hóa, hội nhập quốc tế, PTBV, ứng phó với BĐTC,...; (ii) Lấy ý kiến phản hồi về đào tạo, nghiên cứu khoa học, công nghệ và các hoạt động của Nhà trường, nhất là xây dựng, cập nhật chiến lược, kế hoạch phát triển, chương trình và phương pháp đào tạo, nghiên cứu; (iii) Xây dựng và thực hiện kế hoạch cụ thể hợp tác về đào tạo, nghiên cứu khoa học, chuyển giao tri thức, phát triển và sử dụng hiệu quả các nguồn lực; (iv) Hỗ trợ đào tạo, nghiên cứu khoa học, tạo thêm giá trị gia tăng để phát triển đào tạo, nghiên cứu, chuyển giao tri thức; (v) Nâng cao năng lực đội ngũ cán bộ, khả năng có việc làm của người học; sử dụng và đãi ngộ nguồn nhân lực được đào tạo theo đúng năng lực;

- Tạo môi trường làm việc, học tập thúc đẩy sáng tạo, cống hiến, thực hiện khát vọng nghề nghiệp;

- Phát triển hợp tác quốc tế để nâng cao chất lượng, hiệu quả đào tạo, nghiên cứu khoa học, phát triển công nghệ, chuyển giao tri thức và phát triển các nguồn lực;

- Ưu tiên phát triển đội ngũ cán bộ giảng dạy, nghiên cứu có năng lực và trình độ chuyên môn cao, thích hợp, đáp ứng được các yêu cầu trong nước và quốc tế.

4. Một số khuyến nghị nhằm đổi mới công tác đào tạo và nghiên cứu khoa học, công nghệ EME

\section{1. Đối với cơ sở giáo dục đại học và đơn vị nghiên cứu hỗ trọ}

- Chủ động nghiên cứu tạo nhu cầu mới về đào tạo, nghiên cứu khoa học, công nghệ và nguồn nhân lực EME đáp ứng nhu cầu mới, bối cảnh mới nói trên;

- Tích cực nghiên cứu, dự báo, thông báo các nhu cầu hiện có và mới của các nhà tuyển dụng và sử dụng lao động, các bên liên quan khác về sản phẩm KHCN, nguồn nhân lực EME;

- Mạnh dạn sáng tạo, phát triển các CTĐT mới, cải tiến, nâng cấp các CTĐT và phương pháp dạy học hiện có đáp ứng nhu cầu, yêu cầu mới, bối cảnh mới; tăng cường áp dụng các thành tựu $\mathrm{CMCN} 4.0$ trong đào tạo để nâng cao chất lượng nguồn nhân lực đáp yêu cầu xây dựng 
quốc gia số, chuyển đổi số, kinh tế số,...

- Hợp tác thực sự và hiệu quả với các bên liên quan, tổ chức đào tạo, kiểm định chất lượng và các hoạt động khác liên quan để đáp ứng cao và nhanh hơn yêu cầu, nhu cầu và hài lòng của họ;

- Đảo bảo chất lượng bền vững các hoạt động $\mathrm{KHCN}$ và đào tạo nguồn nhân lực, chuyển giao tri thức EME;

- Nghiên cứu, lựa chọn, chắt lọc, phát triển và vận dụng sáng tạo các bài học hay của các trường đại học trong và ngoài nước về đảm bảo chất lượng, đổi mới hoạt động nghiên cứu khoa học, công nghệ, đào tạo phù hợp với điều kiện cụ thể, sứ mạng, tầm nhìn, thế mạnh của từng đơn vị để nâng cao chất lượng nguồn nhân lực đáp ứng yêu cầu mới, bối cảnh mới, phát triển và đảm bảo chất lượng bền vững EME: (i) Phát triển chuẩn đầu ra: phẩm chất, tầm nhìn, năng lực (sáng tạo, có và tạo việc làm, khởi nghiệp,...), kỹ năng nghề nghiệp, kỹ năng xã hội (mềm) của người học đáp ứng nhu cầu, yêu cầu, hài lòng các bên liên quan, yêu cầu của $\mathrm{CMCN} 4.0$, kinh tế tuần hoàn, $\mathrm{PTBV}$, ứng phó $\mathrm{BĐTC}$, đổi mới toàn diện giáo dục, ...; (ii) Nâng cao năng lực giảng dạy để phát triển chuẩn đầu ra người học nói trên, tạo thêm nhiều sản phẩm sáng tạo đáp ứng yêu cầu CMCN 4.0, PTBV, ứng phó BĐTC; (iii) Phát triển hệ thống hỗ trợ giảng dạy, học tập: thể chế, chính sách khuyến khích đổi mới, sáng tạo hoạt động giảng dạy; cơ sở vật chất, công nghệ dạy học tiên tiến, học liệu, cơ sở dữ liệu, đại học số, đội ngũ cán bộ hỗ trợ, huấn luyện,...

4.2. Đối với các nhà tuyển dụng, sử dụng nguồn nhân lục và sử dụng các sản phẩm KHCN EME

- Chủ động đề xuất, nên rõ nhu cầu, yêu cầu hiện có và tương lai về số lượng, chất lượng (mục tiêu, chuẩn đầu $\mathrm{ra}, . .$. ) đối với $\mathrm{KHCN}$, nguồn nhân lực EME;

- Tích cực tham gia các khâu của $\mathrm{KHCN}$, đào tạo, kiểm định chất lượng EME;

- Sử dụng, đãi ngộ sản phẩm KHCN, người lao động theo đúng chất lượng;

- Tài trợ, hỗ trợ nghiên cứu $\mathrm{KHCN}$, đào tạo nguồn nhân lực EME đáp ứng tốt hơn nhu cầu, yêu cầu, hài lòng của chính mình;

- Các hỗ trợ khác như cùng các cơ sở giáo dục đại học khuyến nghị với Nhà nước phát triển $\mathrm{KHCN}$, nguồn nhân lực EME đáp ứng yêu cầu mới, bối cảnh mới;

- Các doanh nghiệp nên tạo mối liên kết, hợp tác chặt chẽ với cơ sở đào tạo nhân lực để có lực lượng lao động lành nghề phù hợp với mình;

- Doanh nghiệp nên có chiến lược nuôi dưỡng nguồn nhân lực ngay từ khi sinh viên học năm cuối, tạo cơ hội cho sinh viên vào thực tập tại chính doanh nghiệp của mình. Doanh nghiệp có thể yêu cầu đào tạo nguồn nhân lực theo đơn đặt hàng của mình. Như vậy, các trường sẽ tập trung vào đào tạo nguồn nhân lực có chất lượng cao để cung ứng lại cho doanh nghiệp đúng số lượng và chất lượng mà doanh nghiệp cần;

- Các doanh nghiệp có thể tự đào tạo nguồn nhân lực thông qua việc kết hợp với các trường đại học và các cơ sở đào tạo nguồn nhân lực khác,...

\section{3. Đối với các nhà hoạch định chính sách,} quản lý Nhà nước

Khi xây dựng chiến lược, quy hoạch phát triển kinh tế - xã hội, ngành, địa phương cần chỉ rõ nhu cầu sử dụng các sản phẩm KHCN, người lao động đối với từng ngành/chuyên ngành (đặt hàng các sản phẩm KHCN, số lượng, chất lượng nguồn nhân lực EME) tạo tiền đề cho các cơ sở giáo dục đại học xây dựng chiến lược, kế hoạch phát triển $\mathrm{KHCN}$, nguồn nhân lực phù hợp;

Ban hành chính sách: (i) Tuyển dụng, sử dụng, đãi ngộ nguồn nhân lực theo đúng năng lực và chất lượng sản phẩm $\mathrm{KHCN}$; (ii) Hỗ trợ phát triển $\mathrm{KHCN}$, đào tạo nguồn nhân lực EME đáp ứng yêu cầu mới, bối cảnh mới.

Trao cho các cơ sở giáo dục đại học quyền tự chủ, tự chịu trách nhiệm cao phù hợp với năng lực.

\section{Kết luận}

Để đổi mới công tác đào tạo và nghiên cứu khoa học, công nghệ, các cơ sở giáo dục đại học cần lựa chọn, áp dụng sáng tạo các bài học về 


\section{BÀI BÁO KHOA HỌC}

quản trị chất lượng (dựa vào quản trị đại học tiên tiến, mô hình quản trị phối hợp,...), đào tạo dựa theo chuẩn đầu ra, tham vấn, hợp tác toàn diện với các bên liên quan, thực hiện đầy đủ các quy định hiện hành về đảm bảo chất lượng giáo dục đại học theo các thông tư của Bộ Giáo dục và Đào tạo, lựa chọn, áp dụng sáng tạo các bài học hay về phát triển, cải tiến CTĐT phù hợp với đơn vị mình,... Đối với riêng lĩnh vực EME, cần thực hiện quan điểm "Uu tiên đáp ứng cao và nhanh nhu cầu, yêu cầu phát triển đất nước, xã hội, các bên liên quan"; đẩy mạnh kết nối, hợp tác với xã hội, các bên liên quan; tạo môi trường làm việc, học tập thúc đẩy sáng tạo, cống hiến, khát vọng nghề nghiệp; phát triển hợp tác quốc tế; ưu tiên phát triển đội ngũ cán bộ giảng dạy, nghiên cứu có năng lực và trình độ chuyên môn cao, thích hợp, đáp ứng được các yêu cầu nâng cao chất lượng đào tạo, nghiên cứu khoa học, chuyển giao tri thức, từng bước đạt chuẩn khu vực, quốc tế.

Lời cảm ơn: Tập thể tác giả chân thành cảm ơn GS. Nguyễn Viết Thịnh, GS. Truơng Quang Hải, các co quan quản lý Nhà nước, các Doanh nghiệp đã góp nhiều ý kiến quý báu đề hoàn thành bài viết này.

\section{Tài liệu tham khảo}

1. Bộ Giáo dục và Đào tạo (2008), Chiến lược phát triển giáo dục Việt Nam 2009 - 2020.

2. Bộ Giáo dục và Đào tạo (2016), Thông tu 04/2016/TT-BGDĐT, ban hành quy định về tiêu chuẩn đánh giá chất lương chưong trình đào tạo các trình độ của giáo dục đại học

3. Bộ Giáo dục và Đào tạo (2017), Thông tur 12/2017/TT-BGDĐT, ban hành quy định về kiểm định chất lượng co sở giáo dục đại học.

4. Chương trình Phát triển Liên Hợp Quốc - UNDP (2010), Tổng quan Báo cáo phát triển con người. Của cải thực sự của quốc gia: Đường đi, Thành tưu, Thách thức.

5. Đặng H (2005), Kinh tế tri thức: Thời cơ và thách thức đối với sự phát triển của Việt Nam, Nhà xuất bản Chính trị Quốc gia, Hà Nội.

6. Đỗ Hải P (2018), Nhũng vấn đề lý luận về phát triển bền vũng và kinh tế xanh ở Việt Nam. Tạp chí Khoa học ĐHQGHN: Nghiên cứu Chính sách và Quản lý, tập 34, số 2, tr.1-7.

7. Drucker, P.F. (1995), The information executives truly need. InformationWeek, (525), 89-93.

8. Hồ Tú B, 2009, Kinh tế tri thức ở Việt Nam? Diễn đàn Trường Khoa học Tri thức, Viện Khoa học và Công nghệ Tiên tiến Nhật Bản, số 23, Ngày 05.12.2009

9. Nguyễn Văn S (2002), Trí thức giáo dục đại học Việt Nam thời kỳ đẩy mạnh công nghiệp hóa, hiện đại hóa. Nhà xuất bản Chính trị quốc gia, Hà Nội, tr.268.

10. Petrillo, A., Felice, F.D., Cioffi, R., and Zomparelli, F. (2018), Fourth industrial revolution: Current practices, challenges, and opportunities. Digital Transformation in Smart Manufacturing, $1-20$.

11. Quốc Hội (2018), 34/2018/QH14 Luật sưa đổi, bổ sung một số điều của Luật Giáo dục đại hoc.

12. Schroeder, P., Anggraeni, K., and Weber, U. (2018), The relevance of circular economy practices to the sustainable development goals. Journal of Industrial Ecology, 23(1), 77-95.

13. Trần Thị Bảo K (2014), Phát triển giáo dục Đại học ở Việt Nam trong hội nhập quốc tế, Tạp chí Khoa học Xã hội Việt Nam, tập 10, số 83, tr.76.

14. United Nations (2014), Achieving Sustainable Development Goals, Sustainable Development Goals Fund (SDGF), http://www.sdgfund.org/goal-4-quality-education 


\title{
INNOVATION OF TRAINING AND SCIENTIFIC RESEARCH, AND TECHNOLOGY FOR THE ENHANCEMENT OF THE QUALITY OF HUMAN RESOURCE IN THE FIELD OF EARTH - MINE - ENVIRONMENT

\author{
Mai Trong Nhuan ${ }^{1}$, Tran Thanh $\mathrm{Hai}^{2}$, Nguyen Thi Hoang Ha ${ }^{1}$, \\ Tran Hong Thai ${ }^{3}$, Nguyen Tai Tue ${ }^{1}$
}

${ }^{1}$ Vietnam National University

${ }^{2}$ Hanoi University of Mining and Geology

${ }^{3}$ Viet Nam Meteorological and ydrological Administration

\begin{abstract}
: some solutions on innovations of training and scientific research, technology for enhancing human resource capicity in the field of Earth - Mine - Environment (EME). The current trend of sustainable development, green socio-economic with high tolerance, proactive responses to global changes, society demand and job creation after graduation, job requirements by sectors, human resource quality, etc... highlights an urgent need for innovation of higher education training and scientific research, technology, especially in the field of EME. These innovations are aimed at capacity building and job creation, fulfilling new requirement in the mentioned context. In addition, recommendations for higher education institutions and employers on using EME scientific-technological products and human resources are also proposed.
\end{abstract}

Keywords: Innovation, Human resource training, Earth - Mine - Environment, Scientific research. 